\title{
Sport and the Coronavirus Crisis Special Issue: An Introduction
}

\author{
Brody J. Ruihley and Bo Li \\ Miami University, Oxford
}

The world experienced a tremendous amount of challenges and change during the year 2020. Having been first reported on December 31, 2019, a novel coronavirus, named 2019-nCoV or COVID-19 by the World Health Organization (WHO), entered the global landscape, altering the daily lives of nearly everyone in its path. During the early months of 2020, cases began to grow in Asia, hitting China the hardest. As the world watched government actions and news updates out of China, Thailand, Japan, and South Korea, the virus began to make its way across the globe. One would think that tracking the spread of this virus would be noticeable based on symptoms, hospitalizations, and subsequent loss of life for thousands of people. However, COVID-19 presented the health profession, and the world community, with puzzle pieces that often were and are still hidden. What made tracking this virus especially difficult was the potential for asymptomatic carriers and transfer, a 2-week window of contagious activity, and the way the virus was affecting differing age groups. Once the virus began to spread, or cases became further known, European countries and the United States developed into hot spots for virus cases and unfortunate death. As months passed, the virus continued into India, Russia, and major regions in South America and Africa.

The period of March 10-13, 2020, is a key timeline of the coronavirus impact, as the sports world came to screeching halt. Leading up to this sport stoppage, many conversations about fan attendance were being held for high school, college, and professional competition. On March 10, in a decision that many thought to be premature, the Ivy League college basketball conference canceled its men's and women's basketball tournaments. The events of the next 72 hours would prove the Ivy League correct in their decision, as it would be the first of many cancellations. Wednesday, March 11, is one day that many will remember, as it relates to the coronavirus crisis. During this day, the WHO declared the COVID-19 spread a pandemic, the first professional athlete was diagnosed with the virus (Juventus defender, Daniele Rugani), and Americans were hit squarely with the threat of the virus. In the span of an hour, the President of the United States banned travel to and from most of Europe, well-known actors Tom Hanks and Rita Wilson announced they had contracted the virus, and a National Basketball Association (NBA) game

The guest editors are with Miami University, Oxford, OH, USA. Ruihley (brody.ruihley@miamioh .edu) is corresponding author. 
between the Oklahoma City Thunder and Utah Jazz was abruptly canceled and the NBA season eventually suspended after Utah Jazz player, Rudy Gobert, tested positive for the virus.

March 12 did not bring any relief to the sports world, as news only brought on more cancellations and postponements. In this 24-hour span, the Association of Tennis Professionals (ATP), U.S. Major League Soccer (MLS), Professional Golfers' Association (PGA), Ladies Professional Golf Association (LPGA), Major League Baseball (MLB), and the National Hockey League (NHL) all delayed their seasons. In a major decision, the top American college sport governing body, the National Collegiate Athletic Association (NCAA), canceled all remaining winter and spring season sporting events, impacting thousands of coaches and athletes (Weyrich, 2020). In addition to these delays and cancellations, the newly formed XFL (American football league) canceled its 2020 season, ultimately forcing the league to permanently fold. The virus continued to impact the sports world on March 13, as Arsenal FC manager Mikel Arteta tested positive and the English Premier League, NASCAR racing, the Boston Marathon, and golf's The Masters Tournament were all postponed.

Alongside the cancellation or suspensions of recreational, high school, college, and professional sport activities around the world, including the 2020 Olympic and Paralympic Games, there has been a litany of fan reaction, alternative sport program, social and traditional media coverage of the pandemic, and many variations of the sport experience taking place without sport. While the situation is still uncertain, there is a lot to learn about the initial and early impact of the coronavirus crisis on the sport industry. The call for this special issue of the International Journal of Sport Communication carried a bit of uncertainty as we, the coeditors of this issue, asked scholars to contribute scholarly commentaries and analyses of an unfortunate, life-altering pandemic. We were uncertain about the type of response or interest that would follow the call for papers. To our surprise and genuine disbelief, we received 125 full submissions from scholars all over the world. With 125 full-paper submissions, comes a need for 375 blind reviews. We received those reviews and are very appreciative of the $100+$ reviewers assisting in such a short time frame. The input and generosity to serve this academic community was truly inspiring. Thank you to all that volunteered to review! We would also like to extend our gratitude to the Editor of the International Journal of Sport Communication, Paul M. Pedersen, for his organization and commitment to this special issue.

In this issue, we have selected 30 commentaries and 3 industry interviews all providing a wide understanding of how the COVID-19 pandemic has impacted and altered the communication, operation, and management of sport industries all throughout the world. These commentaries come in all shapes and sizes when comparing scope, length, methods, topic, level of sport, and COVID-19 implications and discussion. A goal of this special issue, from the outset, was to give voice to many scholars in their own particular niche of sport-based research and provide a venue to discuss how that niche has been impacted by this global pandemic. We are proud that these goals have been met. We are pleased that these commentaries examine the varied aspects of the sport industry, including topics in communication, marketing, management, coaching, media, public relations (PRs), gender, and governance. 
Many of the commentaries in this special issue focus on the impact of COVID-19 on entire sport industries. Representing this, Smith and Casper's work provides a critical review on how American professional sport leagues' communication is driven by corporate social responsibility (CSR) during this crisis. King's commentary examines professional tennis stakeholder response and how the global pandemic could shape the future of tennis governance. The work of Mirabito, Hardin, and Pate explores the NCAA's effectiveness of their public messaging during the critical time of pandemic uncertainty. With a focus on youth sport, Sanderson and Brown discuss the psychological, developmental, and economic impacts of this particular segment of the sport industry. Using interviews with industry professionals, Ruihley and Chamberlin highlight the work and response of fantasy sport professionals as they operate in an environment with the key missing ingredient of live sport. With many organizations exploring different avenues and answering the call to produce any type of sport content, Goldman and Hedlund provide a view of the American sport industry's shift to new content, rebroadcasted mediated content, and esport. Representing lifestyle sports, Smith outlines the impact of COVID-19 on these types of activities and the challenges of limiting participation and risk.

To have a better understanding of those professionals within the sport business landscape and their perception of the impact of COVID-19 on their own industry, we have selected three industry interviews to be a part of this issue. Son, Williams, and Heo interviewed the PR manager for the Korean Baseball Organization's Kia Tigers to discuss the role of PR in crisis management. Hanna, in his conversation with the ESPN Vice President of Communications, presents discussion on how the cancellation and postponement of sport events impacted ESPN programming. In a final interview, with a social media manager at World in Motion (sport agency based in London), Mountifield and Sharpe explore how this company creates new creative content on social media to engage with fans during a global crisis.

One distinct aspect of the COVID-19 sports landscape was the absolute stoppage of sport. Although some seasons or events were postponed longer than others, fans from all over the globe experienced some sort of disruption to the sport they consume. Another aspect about this pandemic time was the individual and collective need to social distance, self-isolate, or quarantine. As a result, many celebrities, athletes, coaches, and sport organizations were forced to use alternative forms of media or altered messaging to communicate during this unusual time. Many of the commentaries in this special issue focus on sport media and communication covering various topics, including legacy media (television and newspapers), digital media platforms (Twitter, Instagram, and TikTok), athlete representation, crisis communication, fake news, and media framing. Representing this discussion, Buehler assesses programing strategies adopted by sports television networks to address the large hole left over from the loss of live sporting events. Coche and Lynn take us behind the scenes and explore how sport production practices have been impacted by COVID-19. Hull and Romney investigate local sports broadcasters and their adaptation to coverage of sport during the crisis. Li and Scott use Wu Lei's fake news situation to explain how sport misinformation was spread and eventually corrected during COVID-19 in China. Exploring media framing, one commentary compares reporter and fan topics during this sport stoppage, as Curry and Good explore baseball 
conversations in a time with no baseball. Additionally, Clevenger, Rick, and Bustad discuss media framing of the pandemic and anthropocentric narratives that arise from the coverage. The Ultimate Fighting Championship (UFC) created a great amount of content while many sport organizations were on pause. Aptly placed in their title, Butryn, Masucci, and Johnson explore Dana White's strategy in promoting how the UFC show must go on.

In addition to traditional media, social media became a mainstream platform, where athletes, coaches, and sport organizations created links with fans to increase their brand awareness and communicative reach during the pandemic. The work in this issue further illustrates just how important sport media and communication activities are in this time of crisis. Arguing for the usefulness of technology, Whales, Frawley, Cohen, and Nikolova examine stakeholder communication in Australian professional sport. Feder's commentary explores fan-athlete interaction through social media platform, Instagram. Also exploring Instagram, López-Carril and Anagnostopoulos discuss the use of social media by international soccer teams and the role of CSR in the messaging. Examining social media response from sport figures and organizations, Sharpe, Mountifield, and Filo discuss the altruistic tone of communication and how this differs from the usual barrage of entertainment messages. Bringing professional wrestling to this special issue, Davidson, $\mathrm{Du}$, and Giardina explore public sentiments toward the continuation of wrestling during the time of social isolation during a global pandemic. In a cross-cultural analysis of social media use, Su, Baker, Doyle, and Yan explore how TikTok has been used by American athletes and Chinese athletes to engage with sport fans.

As seen by the aforementioned commentaries, this special issue represents many aspects of the global sport industry. The following works further illustrate the impact of COVID-19 on specific international sport markets. Sheptak and Menaker's commentary, as well as Bingaman's, bring attention to how American audiences and media reacted to Australian Football, as one of the only professional sport leagues broadcasted live on American television during the U.S. sport shutdown. Schallhorn and Kunert focus on the German sport market and examine how German TV broadcasts and soccer clubs created unique content during the crisis. In Kristiansen, Dille, and Day's work, an in-depth analysis of the Norwegian Football Association's crisis communication strategies is provided. Exploring coaching in the international context, Callary and her colleagues explore how the global pandemic has impacted coach development practices across many nations.

This special issue brings focus to several important sport-management-related topics. This issue features three commentaries discussing women's sport in the time of this global pandemic. Hartman sheds light on the financial impact caused by COVID-19 on women's college athletics, specifically Title IX compliance. With consideration to interdependence, Pape and McLachlan discuss how the coronavirus pandemic is allowing time to reflect and reveal how gendered structures have developed over time. Last, Staurowsky, Koch, Dury, and Hayes examine women's sport coverage during the crisis and discuss potential women's sport opportunities. In further sport-management-based commentaries, Cianfrone and Kellison provide discussion on volunteer and event management surrounding the NCAA Men's Basketball Final Four and the legacy plan impacted by the COVID-19 pandemic. 
Finally, in a fitting end to this summary section, and to the special issue, Kleimann raises a very interesting question about whether sport PRs should go back to normal once sport organizations are able to resume play and business practice. This work reflects on how the pandemic has created many new ways to connect in different and deeper ways with stakeholders. This question, should we go back to normal, is one that many sport organizations will be asking, as this pandemic has forced new and creative ways to improve health, safety, efficiency, and even effectiveness in the areas of PRs, social media production, sport content importance, and event management practices.

As sport returns and play resumes, there will be many lessons learned during this unusual and unfortunate time the world found itself in. We hope that the work presented in this special issue assists practitioners and scholars alike in their understanding of sport in the coronavirus crisis.

\section{Reference}

Weyrich, M. (2020). Coronavirus' impact on sports: A timeline of cancellations, postponements and positive tests. Retrieved from https://www.nbcsports.com/washington/ wizards/coronavirus-impact-sports-timeline-cancellations-postponements-and-positivetests 